\title{
Avaliação do vício de "tempo longo" de indicadores internos em ensaio de digestão com ruminantes
}

\author{
[Evaluation of internal markers long term bias in a digestion assay with ruminants] \\ E. Detmann ${ }^{1,4}$, A.L. Souza ${ }^{2}$, R. Garcia ${ }^{1,4}$, S.C. Valadares Filho ${ }^{1,4}$ \\ L.S. Cabral ${ }^{3}$, J.T. Zervoudakis ${ }^{3}$ \\ ${ }^{1}$ Departamento de Zootecnia - UFV \\ Av. P.H. Rolfis s/n \\ 36571-000 - Viçosa-MG \\ ${ }^{2}$ Universidade Federal de Mato Grosso - Rondonópolis, MT \\ ${ }^{3}$ Universidade Federal de Mato Grosso - Cuiabá, MT \\ ${ }^{4}$ Bolsista do $\mathrm{CNPq}$
}

\begin{abstract}
RESUMO
Realizou-se um ensaio de digestão com 20 ovinos machos, castrados, para avaliar o viés de "tempo longo" (VTL) dos indicadores internos: matéria seca indigestível (MSi) e fibra em detergente neutro (FDNi) e ácido (FDAi) indigestíveis. O experimento, com duração de 19 dias, foi implementado em delineamento em blocos completos casualizados, com cinco tratamentos (rações concentradas) e quatro blocos. As dietas utilizadas, formuladas para serem isoprotéicas (10\% de proteína bruta), apresentaram $60 \%$ de feno de capim-coastcross e $40 \%$ de concentrado, constituído por milho grão, farelo de soja e casca de café, em diferentes proporções: $0 ; 6,25 ; 12,5 ; 18,75$; e 25\%. A concentração dos indicadores foi estimada em amostras de alimentos, sobras e fezes, por procedimento de incubação ruminal in situ, durante 144 horas. A relação entre consumo e excreção dos indicadores foi realizada pelo ajustamento de modelo de regressão linear simples, de forma independente dos efeitos fixos de tratamentos e blocos. Verificou-se recuperação completa dos indicadores MSi e FDNi (P>0,30), o que indica ausência de VTL. Observou-se VTL de $+25,45 \mathrm{~g} /$ dia para a FDAi $(\mathrm{P}<0,06)$.
\end{abstract}

Palavras-chave: fibra em detergente ácido indigestível, fibra em detergente neutro indigestível, matéria seca indigestível

\begin{abstract}
Long term bias (LTB) of internal markers indigestible dry matter (iDM), and indigestible neutral (iNDF) and acid (iADF) detergent fiber in a digestion assay with ruminants was evaluated. Twenty castrated male ovines were managed in metabolic crates. A completely randomized block design with five treatments (concentrate rations) and four blocks was used. Diets were isonitrogenous diets (10\% of crude protein) were formulated to containing $60 \%$ of coastcross hay and $40 \%$ of concentrate, in dry matter basis. The concentrates were based on corn grain, soybean meal and coffee hulls, in different levels $(0$, $6.25,12.5,18.75$, and 25\%), as fed-basis. The markers contents in feeds, orts, and feces were estimated by a 144 hours in situ rumen incubation procedure. The relationship between markers intake and fecal excretion was accomplished by a simple linear regression model adjustment, independently of the effects of block and treatment. The total iDM and iNDF recovery $(P>.30)$, with LTB free, was observed. The $i A D F$ had $+25.45 \mathrm{~g} /$ day $L T B(P<.06)$.
\end{abstract}

Keywords: indigestible acid detergent fiber, indigestible dry matter, indigestible neutral detergent fiber

Recebido em 10 de maio de 2005

Aceito em 21 de novembro de 2006

E-mail: detmann@ufv.br 


\section{INTRODUÇÃO}

Em estudos centrados no campo de nutrição de ruminantes, a digestibilidade das dietas ofertadas aos animais pode ser estimada indiretamente a partir do conteúdo de constituintes indigestíveis, também denominados indicadores internos, naturalmente presentes nos alimentos. Esse método se baseia no fato de que, à medida que o alimento transita pelo trato gastrintestinal, a concentração desses constituintes amplia-se progressivamente pela remoção de outros componentes por digestão e absorção (Astigarraga, 1997).

A utilização de indicadores em ensaios de digestão propicia a minimização do labor e a interferência sobre o comportamento animal em comparação a procedimentos invasivos (Owens e Hanson, 1992) ou de quantificação total de massa (Detmann et al., 2004).

Embora características ideais sejam teoricamente definidas para que a seleção dos indicadores seja realizada de forma a obterem-se estimativas de digestibilidade exatas e precisas (Kotb e Luckey, 1972; Owens e Hanson, 1992; Van Soest, 1994), constitui fato notório a inexistência de um indicador ideal a todas as situações experimentais. Dessa forma, faculta-se ao pesquisador a escolha pela propriedade que apresente demanda premente ao estudo a ser conduzido.

De modo geral, os indicadores internos apresentam naturalmente algumas das principais características dos indicadores ideais, destacando-se a não influência negativa sobre os sistemas digestivos animal e microbiano, uma vez que esses são constituintes naturais dos alimentos. Dessa forma, a verificação das características ideais sobre indicadores dessa natureza deve centrar-se sobre questões relacionadas à recuperação desses após a submissão aos eventos do trato gastrintestinal.

Segundo Langlands et al. (1963), o vício total no processo de estimação da excreção fecal (e posteriormente da digestibilidade), por intermédio de indicadores, é compreendido pela diferença entre a estimativa obtida e o valor real de excreção fecal, expresso pela equação:

$\mathrm{VT}=\mathrm{EFgs}-\mathrm{EFR}$ (1), em que:
$\mathrm{VT}=$ vício total; EFR = excreção fecal real obtida por coleta total de fezes; e EFgs = excreção fecal estimada por grab samples, ou amostras tomadas diretamente no reto dos animais.

O vício total do processo de estimação da excreção fecal pode ser fracionado em dois diferentes componentes, por intermédio de arranjo simples da equação (1) (Langlands et al., 1963):

$\mathrm{VT}=(\mathrm{EFgs}-\mathrm{EFar})+(\mathrm{EFar}-\mathrm{EFR})=\mathrm{VTC}+\mathrm{VTL} \quad$ (2), em que:

EFar= excreção fecal estimada por intermédio de amostra representativa do total de fezes excretadas; $\mathrm{VTL}=$ vício de "tempo longo"; $\mathrm{VTC}=$ vício de "tempo curto"; e VT, EFgs e $\mathrm{EFR}=$ como definidos anteriormente.

A partir da equação (2), define-se como vício de "tempo curto" a porção do vício total da estimativa de excreção fecal (ou na recuperação do indicador) relativa à obtenção de amostras fecais não-representativas do total de fezes excretadas (Langlands et al., 1963). Sua eliminação depende diretamente da eficiência do delineamento de amostragem fecal adotado.

Por outro lado, define-se com vício de "tempo longo" a capacidade do indicador em ser excretado em quantidade similar à consumida (Langlands et al., 1963), constituindo característica inerente ao próprio indicador. Assim, para os casos em que um indicador apresente VTL nulo, sua aplicação mostrar-se-á segura em estudos de digestão, uma vez que as limitações quanto ao vício total de recuperação podem ser sanadas por adequações nos procedimentos de amostragem fecal, responsáveis pelo vício de "tempo curto" (VTC). Contudo, nos casos em que um indicador apresente VTL significativo, sua aplicação tornar-se-á comprometedora em estudos de digestão, uma vez que não apresentará a característica de recuperação fecal total, demandada para um indicador ideal (Kotb e Luckey, 1972; Owens e Hanson, 1992).

Dessa forma, em estudos nos quais se avalia somente o vício total de recuperação, resultados sofismáticos podem ser obtidos para indicadores com VTL significativo, uma vez que se comentam erros de amostragem que possam 
contrabalançar tal valor, por conferirem VTC com mesmo módulo que o VTL, mas com sinal oposto. Esses resultados podem produzir falsas inferências e, conseqüentemente, reduzir a acurácia da obtenção das estimativas, caso os procedimentos sejam efetivamente adotados.

O vício de "tempo longo" deve constituir-se em característica primária na definição do indicador a ser adotado, visto que adequações no delineamento de amostragem fecal somente poderão ampliar a eficiência do processo de estimação da excreção fecal em situações nas quais se obtém recuperação completa do indicador.

Objetivou-se avaliar o vício de "tempo longo", ou vício atribuído à recuperação, dos indicadores internos matéria seca indigestível (MSi), fibra em detergente neutro indigestível (FDNi) e fibra em detergente ácido indigestível (FDAi), em um ensaio de digestão com ruminantes.

\section{MATERIAL E MÉTODOS}

Foram utilizados 20 ovinos machos, castrados, sem raça definida, manejados em gaiolas individuais de estudos metabólicos. A fase de campo teve duração de 19 dias, sendo os 12 primeiros destinados à adaptação dos animais ao manejo e às dietas.

O experimento foi implementado em delineamento em blocos completos ao acaso, com cinco tratamentos (rações concentradas) e quatro repetições, considerando-se cada animal como unidade experimental, sendo os blocos constituídos a partir de variações de peso vivo entre os animais.

As dietas utilizadas, isoprotéicas $(10 \%$ de proteína bruta), apresentavam, com base na matéria seca (MS), 60\% de feno de capimcoastcross (Cynodon dactilon) e $40 \%$ de concentrado, constituído por milho grão, farelo de soja e casca de café em diferentes proporções, conforme expresso na Tab. 1.

Os animais foram alimentados à vontade duas vezes ao dia, às 7 e 16h, permitindo sobras diárias 5 a $10 \%$ do total de alimentos fornecidos, com acesso à vontade à mistura mineral.

Tabela 1. Composição alimentar das rações concentradas utilizadas nas diferentes dietas experimentais (\% da matéria natural)

\begin{tabular}{lccccc}
\hline & \multicolumn{5}{c}{ Ração concentrada } \\
\cline { 2 - 6 } & $\mathrm{R} 1$ & $\mathrm{R} 2$ & $\mathrm{R} 3$ & $\mathrm{R} 4$ & $\mathrm{R} 5$ \\
\hline Milho grão & 82,25 & 75,75 & 69,25 & 62,75 & 56,25 \\
Farelo de soja & 17,75 & 18,00 & 18,25 & 18,50 & 18,75 \\
Casca de café & 0,00 & 6,25 & 12,50 & 18,75 & 25,00
\end{tabular}

As rações concentradas R1, R2, R3, R4 e R5 correspondem, respectivamente, aos níveis de inclusão de casca de café de $0,6,25,12,50,18,75$ e 25,00 .

Entre o $13^{\circ}$ e o $19^{\circ}$ dias do período experimental, procedeu-se à quantificação e amostragem do total de alimentos fornecidos. Sobras e fezes foram quantificadas e amostradas entre o $14^{\circ}$ e o $20^{\circ}$ dias de avaliação. As fezes foram coletadas de forma total, com auxílio de bolsas coletoras, diariamente, às 8 e $17 \mathrm{~h}$. Após pesagem, as fezes foram homogeneizadas, retirando-se alíquota de cerca de $10 \%$ do total produzido. Todas as amostras foram acondicionadas em sacos plásticos e congeladas $\mathrm{a}-15^{\circ} \mathrm{C}$.
As amostras de alimentos, sobras e fezes foram secas em estufa com ventilação forçada $\left(60^{\circ} \mathrm{C}\right.$ 72 horas), e processadas em moinho de faca com peneira de porosidade $1 \mathrm{~mm}$. Em seqüência, procedeu-se à feitura de amostras compostas proporcionais, com base no peso seco ao ar, em função do animal. As compostas foram posteriormente quantificadas quanto ao seu teor de matéria seca (Silva e Queiroz, 2002).

Alíquotas duplas de 1,2g das amostras compostas foram acondicionadas em sacos de fibra sintética (filter bags 57 - $\mathrm{ANKON}^{\circledR}$ ), previamente 
pesados, e incubadas por 144 horas no rúmen de um novilho mestiço holandês-zebu, alimentado com dieta mista de volumosos e concentrados na proporção de 70:30, com base na matéria seca. Após este período, os sacos foram retirados, lavados em água corrente até o total clareamento da água, levados à estufa ventilada $\left(65^{\circ} \mathrm{C}-72\right.$ horas), novamente retirados, acondicionados em dessecador e pesados, sendo o resíduo obtido considerado como matéria seca indigestível (MSi). Os sacos foram, então, submetidos à fervura em detergente neutro por uma hora (Van Soest e Robertson, 1985), na proporção de 50ml por saco, lavados com água quente e acetona, secos e pesados conforme o procedimento anterior, sendo o novo resíduo considerado como fibra em detergente neutro indigestível (FDNi). Esse procedimento foi novamente realizado, empregando-se, contudo, detergente ácido (Van Soest e Robertson, 1975), obtendo-se o resíduo denominado fibra em detergente ácido indigestível (FDAi). O consumo e a excreção de cada indicador foram obtidos pelos produtos de sua concentração pelas médias de alimentos fornecidos, sobras e excreção fecal. As concentrações médias dos indicadores em amostras de alimentos, sobras e fezes são apresentadas na Tab. 2.

Tabela 2. Concentrações médias ( $\mathrm{g} / \mathrm{kg}$ de matéria seca) dos indicadores internos matéria seca indigestível (MSi), fibra em detergente neutro indigestível (FDNi) e fibra em detergente ácido indigestível (FDAi), em alimentos, sobras e fezes

\begin{tabular}{cccc}
\hline Item & MSi & FDNi & FDAi \\
\hline Feno & 369,8 & 271,2 & 139,0 \\
Concentrado & 102,9 & 65,9 & 49,9 \\
Sobras & 464,6 & 379,8 & 237,9 \\
Fezes & 618,9 & 465,1 & 268,0 \\
\hline
\end{tabular}

Os procedimentos de comparação entre as quantidades ingeridas e excretadas de cada indicador foram realizados de forma independente aos efeitos fixos de tratamentos e blocos, por intermédio do ajustamento de modelo de regressão linear simples das estimativas de excreção sobre as estimativas de consumo, testando-se as estimativas dos parâmetros de regressão sob as seguintes hipóteses:

$$
\begin{array}{ll}
\mathrm{H}_{0}: \beta_{0}=0 & \mathrm{H}_{0}: \beta_{1}=1 \\
\mathrm{H}_{\mathrm{a}}: \beta_{0} \neq 0 & \mathrm{H}_{\mathrm{a}}: \beta_{1} \neq 1
\end{array}
$$

Sob o caso de não-rejeição de ambas as hipóteses de nulidade, concluiu-se pela similaridade entre consumo e excreção, ou seja, ausência de vício de recuperação ou vício de "tempo longo".

\section{RESULTADOS E DISCUSSÃO}

Verificou-se não-rejeição de ambas hipóteses de nulidade avaliadas $(\mathrm{P}>0,30)$ (Tab. 3) para os indicadores internos matéria seca indigestível (MSi) e fibra em detergente neutro indigestível (FDNi), indicando sua recuperação fecal completa e, por conseguinte, VTL nãosignificativo. Esse comportamento pode ser melhor identificado pela proximidade entre as retas de igualdade $(\mathrm{Y}=\mathrm{X})$ e de quadrados mínimos (Fig. 1 e 2).

Embora não se tenha rejeitado a hipótese de nulidade associada ao coeficiente de inclinação $(\mathrm{P}>0,96)$, verificou-se a não-aceitação daquela associada ao intercepto $(\mathrm{P}<0,06)$ para o indicador fibra em detergente ácido indigestível (FDAi) (Tab. 3). Esse fato indica a presença de vício constante sobre as estimativas de excreção de FDAi, independentemente da quantidade ingerida do indicador, comportamento evidenciado pela tendência de paralelismo entre as retas de igualdade e de mínimos quadrados (Fig. 3). Neste caso, a estimativa para o intercepto da relação entre consumo e excreção representa o VTL do indicador $(+25,45 \mathrm{~g} / \mathrm{dia})$. 


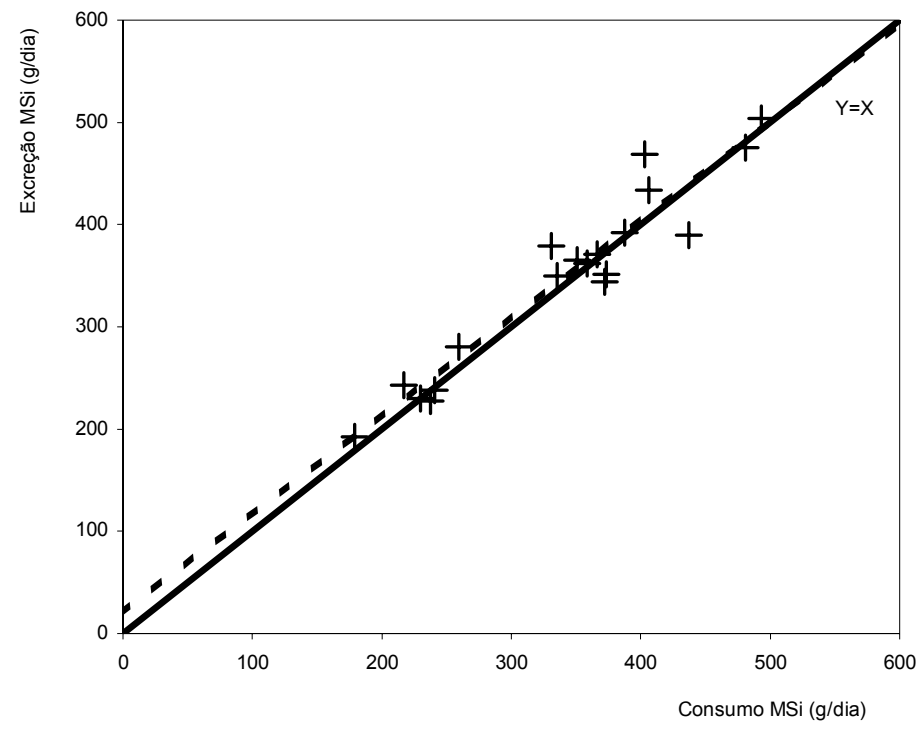

Figura 1. Relação entre consumo e excreção fecal de matéria seca indigestível (MSi) (a linha tracejada corresponde à reta de mínimos quadrados).

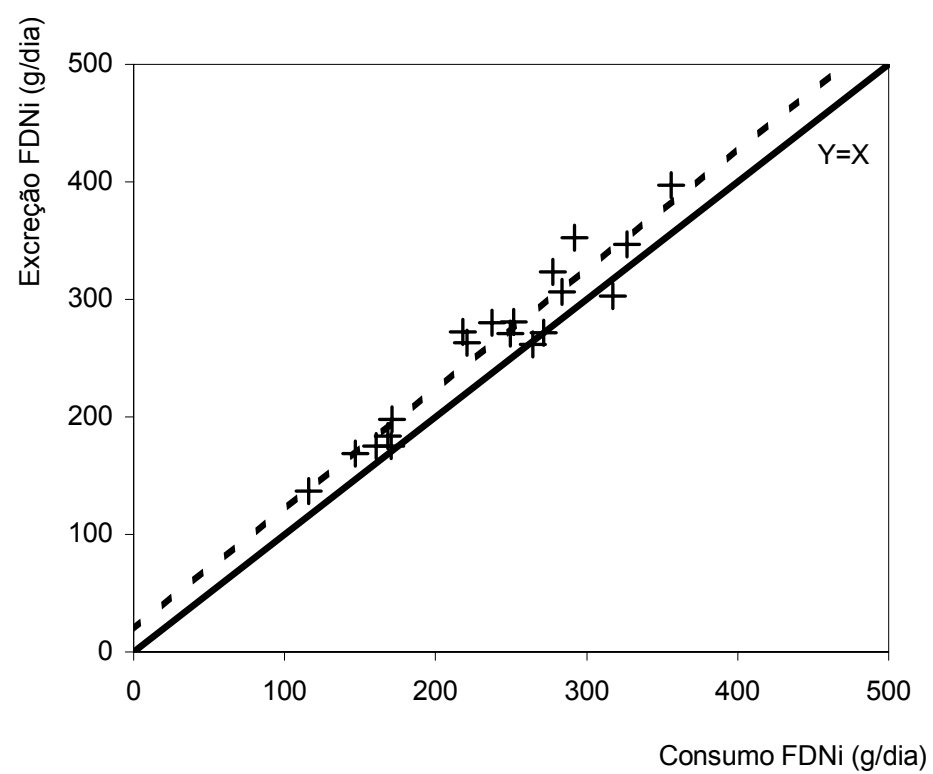

Figura 2. Relação entre consumo e excreção fecal de fibra em detergente neutro indigestível (FDNi) (a linha tracejada corresponde à reta de mínimos quadrados). 
Tabela 3. Médias, estimativas de parâmetros de regressão e níveis descritivos de probabilidade (valor-P) associados às hipóteses de nulidade para as relações entre consumo (variável independente) e excreção (variável dependente) dos indicadores internos matéria seca indigestível (MSi), fibra em detergente neutro indigestível (FDNi) e fibra em detergente ácido indigestível (FDAi)

\begin{tabular}{|c|c|c|c|c|c|c|}
\hline \multirow{3}{*}{ Indicador } & \multirow{2}{*}{\multicolumn{2}{|c|}{ Média }} & \multicolumn{4}{|c|}{ Regressão linear } \\
\hline & & & & & Coeficiente & clinação \\
\hline & Consumo & Excreção & Estimativa & Valor-P $\mathrm{P}^{\mathrm{a}}$ & Estimativa & Valor- $\mathrm{P}^{\mathrm{b}}$ \\
\hline MSi & 339,9 & 347,3 & 19,67 & 0,4252 & 0,9638 & 0,6045 \\
\hline FDNi & 236,8 & 261,4 & 18,70 & 0,3054 & 1,0250 & 0,7333 \\
\hline FDAi & 124,7 & 150,7 & 25,45 & 0,0527 & 1,0044 & 0,9626 \\
\hline
\end{tabular}

$\bar{a} / H_{0}: \beta_{0}=0 ; H_{a}: \beta_{0} \neq 0 . b / H_{0}: \beta_{1}=1 ; H_{a}: \beta_{1} \neq 1$.

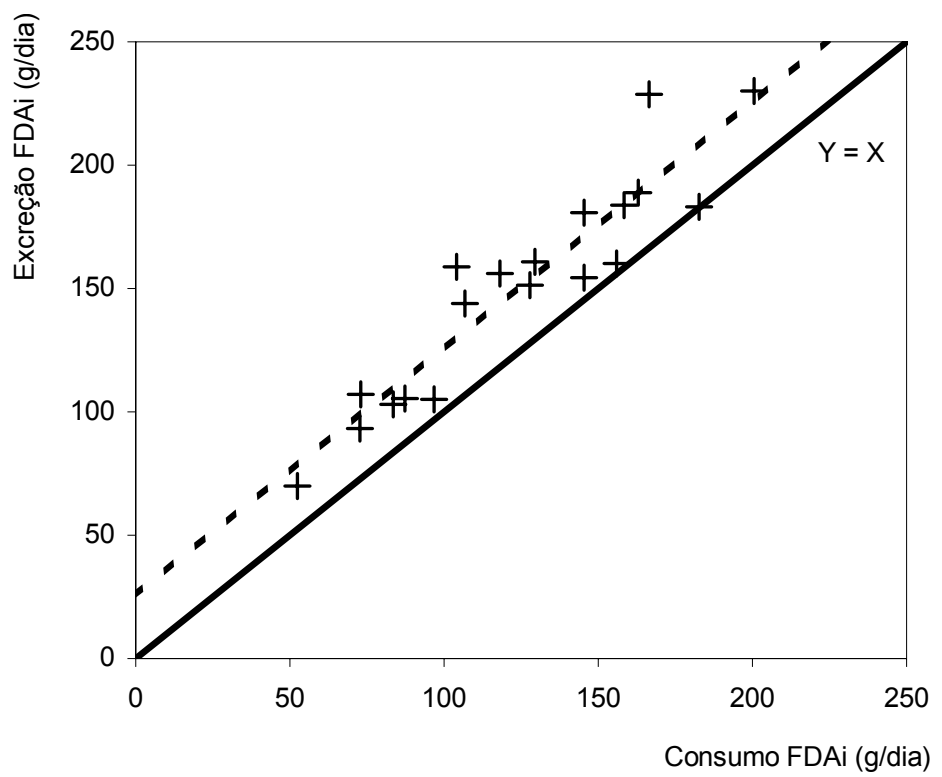

Figura 3. Relação entre consumo e excreção fecal de fibra em detergente ácido indigestível (FDAi) (a linha tracejada corresponde à reta de mínimos quadrados).

Falhas na recuperação fecal de um indicador são comumente representadas por desaparecimento ao longo do trato digestivo, implicando VTL negativos. Contudo, o comportamento verificado para a FDAi indicou recuperação fecal superior $(\mathrm{P}<0,06)$ ao total ingerido (Tab. 3$)$.

Considerando-se estudos de digestibilidade com animais em confinamento, nos quais os indicadores internos constituem a base para obtenção de estimativas de excreção fecal, a ocorrência de VTL positivo, como observado para a FDAi, conduziria a subestimativas de excreção fecal, com conseqüente superestimação dos coeficientes de digestibilidade aparente. Esse comportamento converge, em parte, aos resultados relatados por Ítavo et al. (2002), que verificaram, em duas de três diferentes dietas para bovinos em crescimento, maiores estimativas de digestibilidade aparente, quando utilizada a FDAi como indicador em comparação aos resultados obtidos com a FDNi.

Em estudos com ruminantes em pastejo, os indicadores internos constituem estimadores indiretos da digestibilidade dietética, cujas estimativas são obtidas a partir de valores de excreção fecal com base na utilização de indicadores externos (Detmann et al., 2004). Logo, em razão de a excreção fecal ser obtida de forma independente ao indicador interno, a associação de VTL positivo a este conduziria a superestimativas de consumo do indicador e, conseqüentemente, da matéria seca total. Esse comportamento pode ser verificado por intermédio dos resultados relatados por Detmann et al. (2001), que verificaram maiores estimativas de consumo por bovinos em pastejo, ao 
utilizarem a FDAi, em comparação àquelas obtidas com a utilização da FDNi.

A ocorrência de VTL positivo para a FDAi pode ser, em parte, suportada pelos argumentos apresentados por Detmann et al. (2004), que atribuíram as maiores limitações do uso de componentes indigestíveis como indicadores aos procedimentos analíticos empregados para estimação de sua concentração, os quais poderiam incorrer em avaliações distintas em alimentos e fezes, em função de diferenças na estrutura física de partículas e interferências diferenciadas por procedimentos de secagem.

A inspeção das relações entre consumo e excreção (Fig. 1, 2 e 3) permite evidenciar o afastamento gradativo entre as retas de igualdade e mínimos quadrados quando se migra seqüencialmente da MSi para a FDAi. Este fato parece indicar que os erros sistemáticos provenientes do efeito diferencial do método de avaliação sobre alimentos e fezes pronunciam-se a partir dos indicadores de maior concentração (embora sem efeito significativo). Dessa forma, em razão de a FDAi apresentar a menor concentração em alimentos, sobras e fezes entre os indicadores avaliados, tais erros sistemáticos apresentam-se proporcionalmente mais elevados frente às concentrações observadas, incorrendo em verificação de significância e, conseqüentemente, observação de VTL significativo.

Assim, a menor concentração da FDAi em amostras de alimentos e fezes, em relação aos demais indicadores avaliados neste estudo, pode constituir elemento de deficiência em sua aplicação como indicador, tornando-a mais sensível a erros sistemáticos decorrentes de falhas ou ausência de padronização dos métodos analíticos.

Nesse contexto, padronizações de procedimentos relacionados à avaliação de componentes indigestíveis como indicadores devem constituir alvo de futuras investigações, para entendimento da interferência da estrutura física de partículas sobre as estimativas de concentração dos indicadores.

\section{CONCLUSÕES}

Os indicadores internos matéria seca indigestível e fibra em detergente neutro indigestível apresentam recuperação fecal total, mostrando-se acurados para aplicação em ensaios de digestão com ruminantes. Em função de sua menor concentração, a fibra em detergente ácido indigestível mostra-se sensível a erros sistemáticos advindos de procedimentos analíticos, o que reduz sua acurácia como indicador.

\section{REFERÊNCIAS BIBLIOGRÁFICAS}

ASTIGARRAGA, L. Técnicas para la medición del consumo de rumiantes en pastoreo. In: SIMPÓSIO SOBRE AVALIAÇÃO DE PASTAGENS COM ANIMAIS, 1997, Maringá. Anais... Maringá: UEM, 1997. p. 1-23.

DETMANN, E.; PAULINO, M.F.; ZERVOUDAKIS, J.T. et al. Cromo e indicadores internos na determinação do consumo de novilhos mestiços, suplementados, a pasto. Rev. Bras. Zootec., v.30, p.1600-1609, 2001.

DETMANN, E.; VALADARES FILHO, S.C.; PAULINO, M.F. et al. Avaliação da técnica dos indicadores na estimação do consumo por ruminantes em pastejo. Cad. Tec. Vet. Zootec., n. 45, p.40-57, 2004.

ÍTAVO, L.C.V.; VALADARES FILHO, S.C.; SILVA, F.F. et al. Consumo, degradabilidade ruminal e digestibilidade aparente de fenos de gramíneas do gênero Cynodon e rações concentradas utilizando indicadores internos. Rev. Bras. Zootec., v.31, p.1024-1032, 2002.

KOTB, A.R.; LUCKEY, T.D. Markers in nutrition. Nutr. Abstr. Rev., v.42, p.813-845, 1972.

LANGLANDS, J.P.; CORBETT, J.L.; McDONALD, I. et al. Estimation of the faeces output of grazing animals from the concentration of chromium sexquioxide in a sample of faeces. I.Comparison of estimates from samples taken at fixed times of day with faeces outputs measured directly. Br. J. Nutr., v.17, p.211-218, 1963.

OWENS, F.N.; HANSON, C.F. External and internal markers for appraising site and extent of digestion in ruminants. J. Dairy Sci., v.75, p.26052617, 1992.

SILVA, D.J.; QUEIROZ, A.C. Análise de alimentos. Métodos químicos e biológicos. 3.ed. Viçosa: Editora UFV, 2002. 235p.

VAN SOEST, P.J. Nutritional ecology of the ruminant. 2.ed. Ithaca: Cornell University, 1994. $476 \mathrm{p}$.

VAN SOEST, P.J.; ROBERTSON, J.B. Analysis of forages and fibrous foods. Ithaca: Cornell University, 1985. 202p. 